Article

\title{
Lianqiaoxinoside B, a Novel Caffeoyl Phenylethanoid Glycoside from Forsythia suspensa
}

\section{Hai-Xue Kuang *, Yong-Gang Xia, Jun Liang, Bing-You Yang and Qiu-Hong Wang}

Key Laboratory of Chinese Materia Medica (Heilongjiang University of Chinese Medicine), Ministry of Education, Harbin 150040, China; E-Mails: yonggangxia@163.com (Y.-G.X.); lliangjunn@163.com (J.L.); ybywater@163.com (B.-Y.Y.); qhwang668@sina.com (Q.-H.W.)

* Author to whom correspondence should be addressed; E-Mail: hxkuang@hotmail.com; Tel.: +86-45182193001; Fax: +86-45182110803.

Received: 25 May 2011; in revised form: 21 June 2011 / Accepted: 22 June 2011 /

Published: 4 July 2011

\begin{abstract}
Chemical investigation of the 70\% ethanol extract of the unripe fruits of Forsythia suspensa resulted in the isolation of a novel caffeoyl phenylethanoid glycoside, lianqiaoxinoside $\mathrm{B}$, together with the known compound forsythoside $\mathrm{H}$. The new compound was elucidated to be $1 ", 2 "$-[ $\beta$-(3,4,-dihydroxylphenyl)- $\alpha, \beta$-dioxoethanol]-3"- $O$ caffeoyl- $O-\alpha$-rhamnopyranosyl- $(1 \rightarrow 6)-O-\beta$-glucopyranoside by extensive spectroscopic and chemical studies. Lianqiaoxinoside $\mathrm{B}$ and forsythoside $\mathrm{H}$ showed strong antioxidant and antimicrobial activities in vitro by the 2,2'-azinobis-3-ethylbenzothiazoline-6-sulphonate (ABTS) radical-scavenging assay and plate method. This study can be further extended to exploit for the possible application of caffeoyl phenylethanoid glycosides as the alternative antioxidants and antimicrobial agents of natural origin.
\end{abstract}

Keywords: Forsythia suspensa; caffeoyl phenylethanoid glycoside; antioxidant and antimicrobial activities

\section{Introduction}

Forsythia suspensa (Thunb.) Vahl, a small tree widely distributed in China, Korea, Japan and many European nations, belongs to the family Oleaceae [1]. The fruit of F. suspensa is also called in Chinese "Lianqiao" and has been used for antiinflammatory, diuretic, drainage and antidotal purposes [2]. The 
herb is listed in the Chinese Pharmacopoeia 2010 as an important crude drug and an aqueous extract is also used as a medicine. In previous papers, we reported the isolation of two phenylethanoid glycosides - forsythiaside and lianqiaoxinside A - and four lignans - phillygenin, $(+)$-isolariciresinol, phillyrin and (+)-pinoresinol- $\beta$-D-glucoside - from $F$. suspensa [2,3]. In this paper we report the isolation of lianqiaoxinoside $\mathrm{B}$ and forsythoside $\mathrm{H}$ from a $70 \% \mathrm{EtOH}$ extract of unripe $F$. suspensa fruits. Their chemical structures (Figure 1) were elucidated by HRESIMS, 1D and 2D NMR techniques and chemical methods. The high antioxidant and antimicrobial activities of these two caffeoyl phenylethanoid glycosides were also examined.

Figure 1. Structures of 1 and 2.
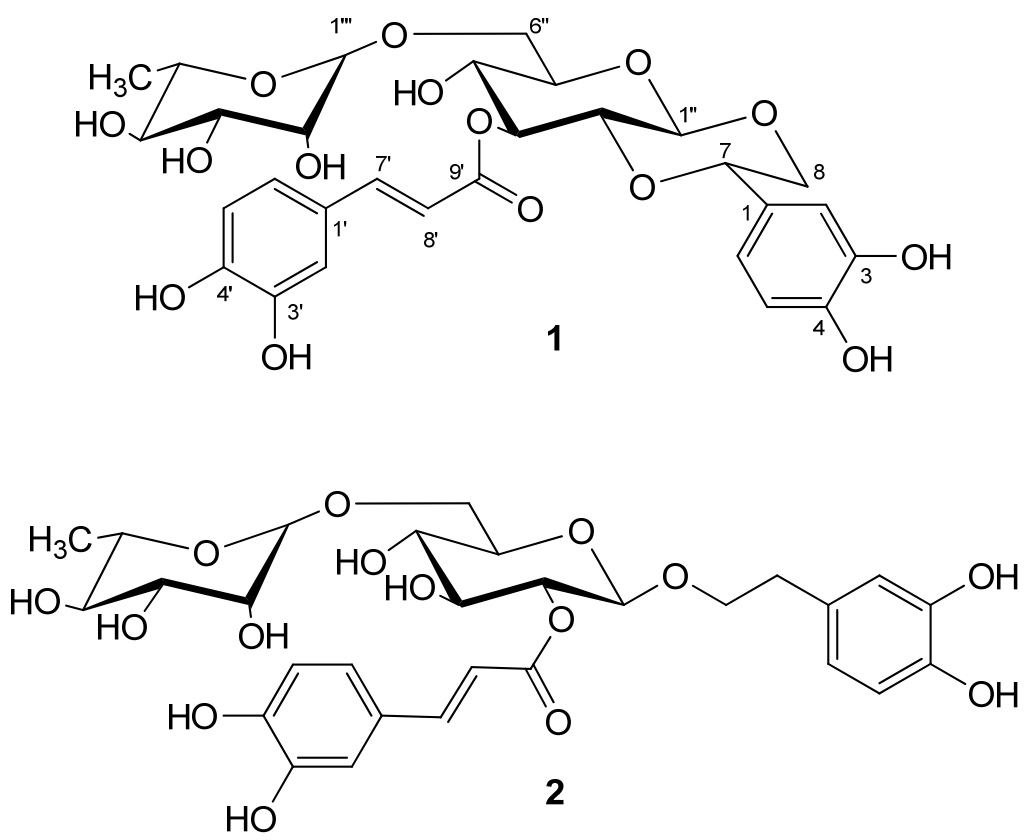

\section{Results and Discussion}

\subsection{Structure Elucidation of 1}

Compound 1 was obtained as a white amorphous powder and showed positive results for the Molish reagent. The UV spectrum of 1 showed absorption band at 222, $246(s h),$.287 (sh.) and $333 \mathrm{~nm}$, respectively, which was considered to correspond to a caffeoyl phenylethanoid glycoside. Its molecular formula was established as $\mathrm{C}_{29} \mathrm{H}_{34} \mathrm{O}_{15}$ by the positive and negative HRESIMS from the

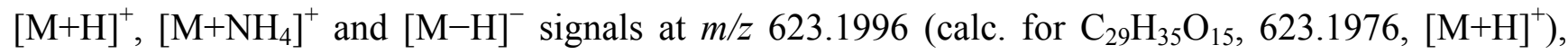
640.2241 (calc. for $\mathrm{C}_{29} \mathrm{H}_{38} \mathrm{NO}_{15}, 640.2241$, $\left[\mathrm{M}+\mathrm{NH}_{4}\right]^{+}$), 621.1816 (calc. for $\mathrm{C}_{29} \mathrm{H}_{33} \mathrm{O}_{15}, 621.1819$, $\left.[\mathrm{M}-\mathrm{H}]^{-}\right)$, respectively, indicating 13 degrees of unsaturation.

The ${ }^{1} \mathrm{H}-\mathrm{NMR}$ spectrum of $\mathbf{1}$ exhibited several characteristic proton signals of the common caffeoyl phenylethanoid glycoside $[\delta 6.78(1 \mathrm{H}, d, J=1.2 \mathrm{~Hz}), 6.69(1 \mathrm{H}, d, J=8.2 \mathrm{~Hz})$, and $6.66(1 \mathrm{H}, d d, J=8.2$, $1.2 \mathrm{~Hz})$; and $6.73(1 \mathrm{H}, d, J=8.2 \mathrm{~Hz}), 6.91(1 \mathrm{H}, d d, J=8.2,2.0 \mathrm{~Hz})$ and $7.01(1 \mathrm{H}, d, J=2.0 \mathrm{~Hz})]$, a pair of trans-olefinic protons [ $\delta 7.55$ and 6.25 (each $1 \mathrm{H}, d, J=16.0 \mathrm{~Hz}$ )]. In addition, two doublet signals due to anomeric protons at $\delta 4.51(1 \mathrm{H}, d, J=7.6 \mathrm{~Hz})$, and $4.73(1 \mathrm{H}, d, J=0.8 \mathrm{~Hz})$, suggested a diglycosidic structure for $\mathbf{1}$. The glucose and rhamnose were further confirmed by ultra-performance 
liquid chromatography analysis based on pre-column derivatization with PMP reagent after acid hydrolysis of $\mathbf{1}$. The configurations of the anomeric protons of glucose and rhamnose were proposed as $\beta$ and $\alpha$, respectively, on the basis of their coupling constants.

${ }^{\mathrm{I}} \mathrm{C}$-NMR spectrum and DEPT experiments of 1 showed 29 signals: one methyl, two methylenes, 19 methines and seven quaternary carbons, of which the signals at $(\delta 127.8,115.5,146.9,149.8,116.5$, $123.1,147.8,114.6,168.2)$ were attributed to the caffeoyl group. The caffeoyl site was established unambiguously by a HMBC experiment in which a long-range correlation between $\mathrm{H}-3$ " $[\delta 5.25(1 \mathrm{H}, t$, $J=8.8 \mathrm{~Hz})]$ of the glucopyranosyl unit and the C-9' $(\delta 168.2)$ of the caffeoyl residue was apparent (Figure 2). The rhamnopyranosyl site was established unambiguously by a HMBC experiment in which a long-range correlation between $\mathrm{H}-1^{\prime \prime \prime}[\delta 4.73(1 \mathrm{H}, d, J=0.8 \mathrm{~Hz})]$ of the rhamnopyranosyl unit and the C-6" ( $\delta$ 67.8) of the glucopyranosyl was apparent. Taking into account the NMR spectral data and the 13 degrees of unsaturation calculated from the empirical formula of $\mathbf{1}$, it was suggested that $\mathbf{1}$ had another alicyclic ring except for an $\alpha, \beta$-unsaturation carbonyl group, two aromatic rings, one rhamnosyl and one glucosyl. The linkage site of the additional ring was determined on the basis of the obvious HMBC correlations between H-1"/C-8, H-8/C-1", H-2"/C-7 and H-7/C-2", respectively.

Figure 2. Key ${ }^{1} \mathrm{H}-{ }^{1} \mathrm{H}$ COSY and $\mathrm{HMBC}$ correlations of $\mathbf{1}$.

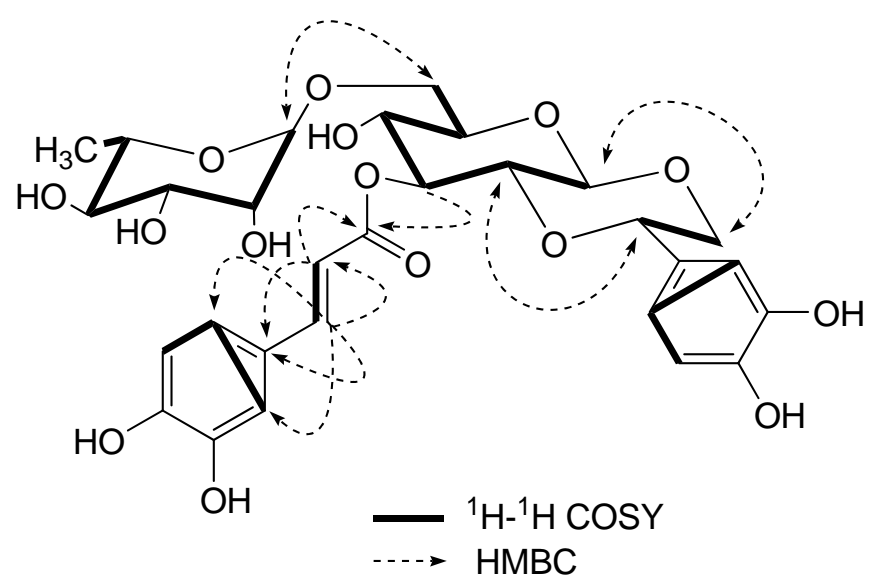

The relative stereochemistry of $\mathbf{1}$ was established by the coupling constants and NOESY correlations. The correlations of H-1" with H-8a and H-3", H-2" with H-7 and H-4" indicated that the glucopyranosyl and alicyclic rings all had a chair conformation with trans-fused ring junctions. In the ${ }^{1} \mathrm{H}-\mathrm{NMR}$, the doublet at $\delta 4.51(1 \mathrm{H}, d, J=7.6 \mathrm{~Hz})$ suggested that the glucose was in the $\beta$-configuration, as well as the large coupling constant $(J=10.2 \mathrm{~Hz})$ also indicated that $\mathrm{H}-7$ and $\mathrm{H}-8 \mathrm{a}$ were similar to $\mathrm{H}-1^{\prime}$ and $\mathrm{H}-2$ ' in trans-axial orientation.

All the hydrogen and carbon signals of $\mathbf{1}$ have been fully assigned by combination of DEPT, ${ }^{1} \mathrm{H}-{ }^{1} \mathrm{H}$ COSY, HSQC, HMBC and NOESY experiments and comparison of spectral data with caffeoyl phenylethanoid glycosides reported in the literature [4]. The shift value for C-2 ( $\delta 74.3)$ is found at a remarkably high field when compared with similar compounds [4], however, we considered that it is possibly due to the shielding effect of the caffeoyl group in the C-3 oxygen atom. The structure of 1 was thus assigned as 1",2"-[ $\beta(3,4$, ,dihydroxylphenyl)- $\alpha, \beta$-dioxoethanol]-3"-Ocaffeoyl-O- $\alpha$-rhamnopyranosyl-( $1 \rightarrow 6)$-O- $\beta$-glucopyranoside, and was named lianqiaoxinoside $\mathrm{B}$. 


\subsection{In Vitro Antimicrobial Activity}

When studying the influence of the concentration of lianqiaoxinoside $\mathrm{B}$ and forsythoside $\mathrm{H}$ on the antimicrobial activities against bacterial strains we used two-fold microdilution broth method. The MIC data of the two compounds were presented in Table 1. The results showed both lianqiaoxinoside $\mathrm{B}$ and forsythoside $\mathrm{H}$ had high antimicrobial activities against the four common bacteria $B$. vulgare, A. bacillus, M. pneumonia and B. dysenteriae.

Table 1. Antimicrobial activity of different constituents of $F$. suspensa (MIC: $\mu \mathrm{g} / \mathrm{mL}$ ).

\begin{tabular}{lccc}
\hline & $\mathbf{1}$ & $\mathbf{2}$ & Cefalexin \\
\hline S. aureus & $>200$ & $>200$ & 8.0 \\
E. coli & $>200$ & $>200$ & 4.0 \\
B. streptococci & 54.0 & $>200$ & 8.0 \\
B. vulgare & 27.5 & 38.2 & 0.5 \\
A. bacillus & 31.5 & 36.5 & 0.5 \\
M. pneumoniae & 28.5 & 42.5 & 0.5 \\
S. albus & $>200$ & $>200$ & 8.0 \\
B. dysenteriae & 36.7 & 30.2 & 0.5 \\
\hline
\end{tabular}

\subsection{Antioxidant Activity}

Recently, the significance of phenolic compounds as dietary antioxidants has been highlighted by experts [5-7]. The amount of phenol hydroxyls and amount of intramolecular H-bonding in a molecule play a key role in its antioxidant activity [5]. Many researchers have reported the strong antioxidant activity of rutin and chlorogenic acid. They are common natural phenolic antioxidants and they all have ortho-substituted hydroxyl structures [6]. The compounds lianqiaoxinoside $\mathrm{B}$ and forsythoside $\mathrm{H}$ exhibited significant ABTS radical scavenging ability, evidencing $\mathrm{IC}_{50}$ values of 15.6 and $17.7 \mu \mathrm{g} / \mathrm{mL}$ (Figure 3), compared with a positive control, $\mathrm{Vc}\left(\mathrm{IC}_{50} 6.8 \mu \mathrm{g} / \mathrm{mL}\right)$. Recently many researches have demonstrated that forsythiaside, which is the marker and major constituent in this plant, possesses strong antioxidant activities [7]. Moreover, lianqiaoxinoside B and forsythoside $\mathrm{H}$ yielded nearly the same antioxidant activities. Obviously, all of these phenylethanoid glycosides have two ortho-substituting hydroxyl groups in both the caffeoyl and phenylethanoid moieties, which could be an important factor for their high antioxidant activity.

Figure 3. Scavenging effects of samples on ABTS radicals.

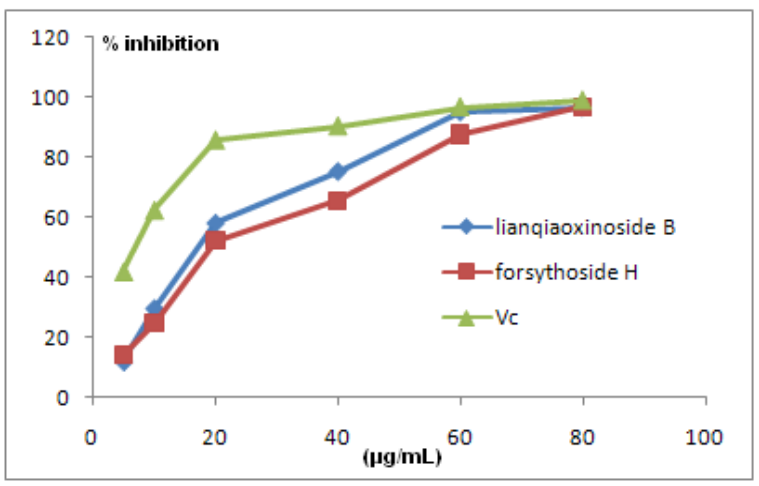




\section{Experimental Section}

\subsection{General}

IR spectra were recorded on a Shimadzu FTIR-8400S spectrometer. NMR spectra were recorded on a Bruker DPX 400 NMR instrument (400 MHz for ${ }^{1} \mathrm{H}-\mathrm{NMR}$ and $100 \mathrm{MHz}$ for ${ }^{13} \mathrm{C}-\mathrm{NMR}$ ). Chemical shifts are given as $\delta$ values with reference to tetramethylsilane (TMS) as internal standard, and coupling constants are given in Hz. HRESIMS were carried out on Waters Xevo QTOF mass spectrometer. Preparative HPLC (Waters, Delta 600-2487) was performed on a Hypersil-ODS II (10 m, $20 \times 300$ mm, Yilite, Dalian, People's Republic of China).

\subsection{Plant Material}

The unripe fruits of F. suspensa were collected in March 2008 from Henan Province, China and identified by Prof. Wang Zhen-yue of Heilongjiang University of Chinese Medicine. The voucher specimen (2008009) was deposited at Herbarium of Heilongjiang University of Chinese Medicine, Harbin, China.

\subsection{Extraction and Isolation}

The unripe fruits of $F$. suspensa $(10 \mathrm{~kg})$ were ground and extracted under reflux conditions with $70 \% \mathrm{EtOH}(30 \mathrm{~L} \times 3 \times 2 \mathrm{~h}$ each). The combined $70 \% \mathrm{EtOH}$ extracts were evaporated to near dryness under vacuum and the resulting mixture $(500 \mathrm{~g})$ was suspended in $\mathrm{H}_{2} \mathrm{O}$ and partitioned successively with petroleum ether $(3 \times 2 \mathrm{~L}), \mathrm{CH}_{2} \mathrm{Cl}_{2}(3 \times 2.5 \mathrm{~L})$, EtOAc $(3 \times 2.5 \mathrm{~L})$ and $n$-BuOH $(3 \times 2.5 \mathrm{~L})$. The $n$-BuOH fraction $(90 \mathrm{~g})$ was applied to a silica gel column chromatography with $\mathrm{CH}_{2} \mathrm{Cl}_{2} / \mathrm{MeOH}$ $(15: 1 \rightarrow 1: 1, v / v)$ gradient to give fractions $\mathrm{B} 1 \rightarrow \mathrm{B} 7$. Fraction B4 (18 g) was subjected to ODS column chromatography with $\mathrm{MeOH} / \mathrm{H}_{2} \mathrm{O}(1: 4 \rightarrow 1: 0, v / v)$ to yield ten sub-fractions $\mathrm{C} 1 \rightarrow \mathrm{C} 10$. Fraction $\mathrm{C} 1$ (300 mg) was purified by preparative HPLC on a Hypersil-ODS II column $(10 \mu \mathrm{m}, 20 \mathrm{~mm} \times 300 \mathrm{~mm}$, flow rate $8 \mathrm{~mL} \cdot \mathrm{min}^{-1}$ ) with $\mathrm{MeOH} / \mathrm{H}_{2} \mathrm{O}(35: 65)$ to afford $\mathbf{1}\left(10 \mathrm{mg}, t_{\mathrm{R}}=12.6 \mathrm{~min}\right)$ and $2(30 \mathrm{mg}$, $\left.t_{\mathrm{R}}=14.3 \mathrm{~min}\right)$. Lianqiaoxinoside $B(\mathbf{1})$ : White amorphous powder, $[\alpha]_{\mathrm{D}}^{25}=+20.8(\mathrm{c}=0.1, \mathrm{MeOH})$. IR $(\mathrm{KBr}): v_{\max }=3399,1698,1607,1523,1282,1117,1055,981,813 \mathrm{~cm}^{-1}$. HRESIMS (positive): $m / z=623.1996$ (calc. for $\mathrm{C}_{29} \mathrm{H}_{35} \mathrm{O}_{15}, 623.1976,[\mathrm{M}+\mathrm{H}]^{+}$), 640.2241 (calc. for $\mathrm{C}_{29} \mathrm{H}_{38} \mathrm{NO}_{15}, 640.2241$, $\left[\mathrm{M}+\mathrm{NH}_{4}\right]^{+}$). HRESIMS (negative): $m / z=621.1816$ (calc. for $\left.\mathrm{C}_{29} \mathrm{H}_{33} \mathrm{O}_{15}, 621.1819,[\mathrm{M}-\mathrm{H}]\right]$ ). ${ }^{1} \mathrm{H}-$ and ${ }^{13} \mathrm{C}-\mathrm{NMR}$ : see Table 2. Forsythoside $H(\mathbf{2})$ : White amorphous powder, $[\alpha]{ }_{\mathrm{D}}^{25}=-15.7$ (c $=0.1$, $\mathrm{MeOH})$. IR $(\mathrm{KBr}): v_{\max }=3413,1691,1604,1512,1449,1338,1283,1036 \mathrm{~cm}^{-1}$. HRESIMS (negative): $m / z=623.1954$ (calc. for $\mathrm{C}_{29} \mathrm{H}_{35} \mathrm{O}_{15}, 623.1976,[\mathrm{M}-\mathrm{H}]^{-}$). ${ }^{1} \mathrm{H}$ - and ${ }^{13} \mathrm{C}-\mathrm{NMR}$ : see Table 2.

\subsection{Determination of the in-Vitro Antimicrobial Activity}

The experimental strains Staphylococcus aureus, Escherichia coli, Beta-hemolytic streptococci, Bacterium vulgare, Aeruginosus bacillus, Micrococcus pneumoniae, S. albus and B. dysenteriae were supplied by the Molecular Microbiology Laboratory of Heilongjiang University of Chinese Medicine. All the strains were tested for purity by Gram staining and by biochemical tests. The strains were kept at $-70{ }^{\circ} \mathrm{C}$ in $\mathrm{LB}$ agar, activated by transferring into nutritive agar, and incubating at $37 \pm 1.0{ }^{\circ} \mathrm{C}$ for $18 \mathrm{~h}$. 
The antimicrobial activity against eight bacterial strains under different concentrations was determined by the plate method. A two-fold microdilution broth method was used to determinate the minimum inhibitory concentration (MIC) value. Details how to determine the antimicrobial activity were provided in a previously published paper [3].

Table 2. ${ }^{1} \mathrm{H}$ - and ${ }^{13} \mathrm{C}-\mathrm{NMR}$ data of $\mathbf{1}$ and $\mathbf{2}$ in $\mathrm{CD}_{3} \mathrm{OD}$ at $400 \mathrm{MHz}$ and $100 \mathrm{MHz}, J$ in $\mathrm{Hz}$.

\begin{tabular}{|c|c|c|c|c|}
\hline \multirow{2}{*}{ No. } & \multicolumn{2}{|l|}{1} & \multicolumn{2}{|l|}{2} \\
\hline & $\delta_{H}$ & $\boldsymbol{\delta}_{\mathrm{C}}$ & $\boldsymbol{\delta}_{\mathbf{H}}$ & $\boldsymbol{\delta}_{\mathbf{C}}$ \\
\hline 1 & & 129.8 & & 131.4 \\
\hline 2 & $6.78(1 \mathrm{H}, d, J=1.2 \mathrm{~Hz})$ & 115.1 & $6.59(1 \mathrm{H}, d, J=1.6 \mathrm{~Hz})$ & 117.0 \\
\hline 3 & & 146.3 & & 146.0 \\
\hline 4 & & 146.6 & & 144.6 \\
\hline 5 & $6.69(1 \mathrm{H}, d, J=8.2 \mathrm{~Hz})$ & 116.4 & $6.57(1 \mathrm{H}, d, J=8.0 \mathrm{~Hz})$ & 116.3 \\
\hline 6 & $6.66(1 \mathrm{H}, d d, J=8.2,1.2 \mathrm{~Hz})$ & 119.5 & $6.48(1 \mathrm{H}, d d, J=8.0,1.6 \mathrm{~Hz})$ & 121.4 \\
\hline 7 & $4.50(1 \mathrm{H}, d d, J=10.2,2.8 \mathrm{~Hz})$ & 78.7 & $2.67(2 \mathrm{H}, t, J=7.2 \mathrm{~Hz})$ & 36.7 \\
\hline \multirow[t]{2}{*}{8} & $3.90(1 \mathrm{H}, d d, J=12.0,2.8 \mathrm{~Hz})$ & 72.6 & $3.94(1 \mathrm{H}, m)$ & 72.0 \\
\hline & $3.61(1 \mathrm{H}, d d, J=12.0,10.2 \mathrm{~Hz})$ & & $3.63(1 \mathrm{H}, m)$ & \\
\hline $1^{\prime}$ & & 127.8 & & 127.8 \\
\hline $2^{\prime}$ & $7.01(1 \mathrm{H}, d, J=2.0 \mathrm{~Hz})$ & 115.5 & $7.06(1 \mathrm{H}, d, J=1.2 \mathrm{~Hz})$ & 115.2 \\
\hline $3^{\prime}$ & & 146.9 & & 146.8 \\
\hline $4^{\prime}$ & & 149.8 & & 149.6 \\
\hline $5^{\prime}$ & $6.73(1 \mathrm{H}, d, J=8.2 \mathrm{~Hz})$ & 116.5 & $6.77(1 \mathrm{H}, d, J=8.4 \mathrm{~Hz})$ & 116.5 \\
\hline $6^{\prime}$ & $6.91(1 \mathrm{H}, d d, J=8.2,2.0 \mathrm{~Hz})$ & 123.1 & $6.91(1 \mathrm{H}, d d, J=8.4,1.2 \mathrm{~Hz})$ & 123.0 \\
\hline $7^{\prime}$ & $6.25(1 \mathrm{H}, d, J=16.0 \mathrm{~Hz})$ & 147.8 & $6.27(1 \mathrm{H}, d, J=16.0 \mathrm{~Hz})$ & 147.1 \\
\hline $8^{\prime}$ & $7.55(1 \mathrm{H}, d, J=16.0 \mathrm{~Hz})$ & 114.6 & $7.56(1 \mathrm{H}, d, J=16.0 \mathrm{~Hz})$ & 115.2 \\
\hline $9^{\prime}$ & & 168.2 & & 168.4 \\
\hline $1^{\prime \prime}$ & $4.51(1 \mathrm{H}, d, J=7.6 \mathrm{~Hz})$ & 99.9 & $4.49(1 \mathrm{H}, d, J=8.0 \mathrm{~Hz})$ & 102.4 \\
\hline $2^{\prime \prime}$ & $3.40(1 \mathrm{H}, m)$ & 74.3 & $4.80(1 \mathrm{H}, t, J=8.0 \mathrm{~Hz})$ & 75.1 \\
\hline $3^{\prime \prime}$ & $5.25(1 \mathrm{H}, t, J=8.8 \mathrm{~Hz})$ & 76.0 & $3.56(1 \mathrm{H}, t, J=8.8 \mathrm{~Hz})$ & 76.2 \\
\hline $4^{\prime \prime}$ & $3.62(1 \mathrm{H}, m)$ & 70.2 & $3.38(1 \mathrm{H}, m)$ & 71.7 \\
\hline $5^{\prime \prime}$ & $3.67(1 \mathrm{H}, m)$ & 78.5 & $3.44(1 \mathrm{H}, m)$ & 76.9 \\
\hline \multirow[t]{2}{*}{$6^{\prime \prime}$} & $3.45(1 \mathrm{H}, d d, J=11.2,5.2 \mathrm{~Hz})$ & 67.8 & $3.65(1 \mathrm{H}, d d, J=10.8,5.0 \mathrm{~Hz})$ & 67.9 \\
\hline & $3.72(1 \mathrm{H}, d d, J=11.2,1.7 \mathrm{~Hz})$ & & $4.00(1 \mathrm{H}, d d, J=10.8,1.2 \mathrm{~Hz})$ & \\
\hline $1^{\prime \prime \prime}$ & $4.73(1 \mathrm{H}, d, J=0.8 \mathrm{~Hz})$ & 102.3 & $4.74(1 \mathrm{H}, d, J=1.6 \mathrm{~Hz})$ & 102.2 \\
\hline $2^{\prime \prime \prime}$ & $3.85(1 \mathrm{H}, m)$ & 72.0 & $3.84(1 \mathrm{H}, m)$ & 72.3 \\
\hline $3^{\prime \prime \prime}$ & $3.70(1 \mathrm{H}, m)$ & 72.4 & $3.70(1 \mathrm{H}, m)$ & 72.2 \\
\hline $4^{\prime \prime \prime}$ & $3.37(1 \mathrm{H}, m)$ & 74.0 & $3.37(1 \mathrm{H}, m)$ & 74.0 \\
\hline $5^{\prime \prime \prime}$ & $3.71(1 \mathrm{H}, m)$ & 69.9 & $3.70(1 \mathrm{H}, m)$ & 69.8 \\
\hline $6^{\prime \prime \prime}$ & $1.26(1 \mathrm{H}, d, J=6.5 \mathrm{~Hz})$ & 18.0 & $1.26(1 \mathrm{H}, d, J=6.0 \mathrm{~Hz})$ & 18.1 \\
\hline
\end{tabular}

\subsection{ABTS Radical-Scavenging Assay}

The radical scavenging capacity of antioxidant for the ABTS (2,2'-azinobis-3-ethylbenzothiazoline6-sulphonate) radical action was determined as previously described [5-7]. ABTS was generated by mixing $7 \mathrm{mM}$ of ABTS at $\mathrm{pH} 7.4\left(5 \mathrm{mM} \mathrm{NaH}_{2} \mathrm{PO}_{4}, 5 \mathrm{mM} \mathrm{Na}_{2} \mathrm{HPO}_{4}\right.$ and $\left.154 \mathrm{mM} \mathrm{NaCl}\right)$ with $2.5 \mathrm{mM}$ potassium persulfate (final concentration) followed by storage in the dark at room temperature for $16 \mathrm{~h}$ 
before use. The mixture was diluted with ethanol to give an absorbance of $0.70 \pm 0.02$ units at $734 \mathrm{~nm}$ using spectrophotometer (Helios, Unicam, Cambridge UK). For each sample, the diluted methanol solution of essential oil $(100 \mu \mathrm{L})$ was allowed to react with fresh ABTS solution $(900 \mu \mathrm{L})$, and then the absorbance was measured 6 min after initial mixing. Ascorbic acid was used as a standard. The capacity of free radical scavenging was expressed by $\mathrm{IC}_{50}(\mathrm{mg} / \mathrm{L})$ value, which represents the concentration required to scavenge $50 \%$ of ABTS radicals. The free radical scavenging activity of each solution was then calculated as percent inhibition according to the following equation: \%inhibition $=100($ A (blank)-A (sample) $) /$ A (blank).

\subsection{Acid Hydrolysis and Derivatization with PMP Reagent}

An aliquot of each sample $(1.0 \mathrm{mg})$ was dissolved in $2 \mathrm{M}$ TFA $(2 \mathrm{~mL})$ in a $5 \mathrm{~mL}$ ampoule. The ampoule was sealed under a nitrogen atmosphere and kept in boiling water bath to hydrolyze samples into aglycone part and monosaccharides for $10 \mathrm{~h}$. After the ampoule was cooled to room temperature, the reaction mixture was centrifuged at 3,000 rpm for $5 \mathrm{~min}$. The supernatant was collected and methanol $(1.5 \mathrm{~mL})$ was added into it for the reaction mixture to be evaporated to dryness under a reduced pressure. Then the same amount of methanol was again added and dried by the same method as above, and the procedure was repeated thrice for TFA to be removed. The hydrolyzed and dried sample solutions were diluted with distilled water $(2 \mathrm{~mL})$ for the following experiments.

Two hundred $\mu \mathrm{L}$ of the hydrolyzed above sample was placed in $2.0 \mathrm{~mL}$ centrifuge tubes, then $0.5 \mathrm{M}$ methanol solution $(100 \mu \mathrm{L})$ of PMP and ammonia $(200 \mu \mathrm{L})$ were added to each. Each mixture was allowed to react for $30 \mathrm{~min}$ in a $70{ }^{\circ} \mathrm{C}$ water bath, then cooled to room temperature and neutralized with formic acid $(200 \mu \mathrm{L})$. The resulting solution was separated by liquid-liquid extraction using a volume of isoamyl acetate (two times) and chloroform (one time), respectively. After being shaken vigorously and centrifuged, the organic phase was carefully discarded to remove the excess reagents. Then the aqueous layer was filtered through a $0.22 \mu \mathrm{m}$ membrane and diluted with water before UPLC analysis. The glucose and rhamnose were identified in 1 and 2 (rhamnose, $t_{\mathrm{R}} 2.03 \mathrm{~min}$; glucose $t_{\mathrm{R}} 4.08 \mathrm{~min}$ ). Details of the UPLC procedure can be seen our previous published paper [8].

\section{Conclusions}

Caffeoyl phenylethanoid glycosides are a category of important botanical ingredients which are extracted from many herb plants. As a part of our chemical investigation on the unripe fruits of F. suspensa, we have isolated a novel caffeoyl phenylethanoid glycoside with a 7,2"-epoxy moiety and one known compound, forsythoside $\mathrm{H}$. Their structures were established on the basis of spectroscopic and chemical evidence. It is also the first time the NMR data of forsythoside $\mathrm{H}$ in $\mathrm{CD}_{3} \mathrm{OD}$ is reported, which showed obvious difference with the spectrum in DMSO- $d_{6}$ recorded in reference [9]. The pharmacological tests showed that they both exhibited high antioxidant and antimicrobial activities. This study can be further extended to exploit for the possible application of caffeoyl phenylethanoid glycosides as the alternative antioxidants and antimicrobial agents from natural origin. 


\section{Acknowledgements}

This work was financed by the Pharmacopoeia Commission of the People's Republic of China.

\section{Conflict of Interest}

The authors declare no conflict of interest.

\section{References}

1. Tropicos. Missouri Botanical Garden. Available online: http://www.tropicos.org/NameSearch.aspx (accessed on 22 May 2011).

2. Xia, Y.G.; Yang, B.Y.; Wang, Q.H.; Liang, J.; Wei, Y.H.; Yu, H.D.; Zhang, Q.B.; Kuang, H.X. Quantitative analysis and chromatographic fingerprinting for the quality evaluation of Forsythia suspensa extract by HPLC coupled with photodiode array detector. J. Sep. Sci. 2009, 32, 4113-4125.

3. Kuang, H.X.; Xia, Y.G.; Yang, B.Y.; Liang, J.; Zhang, Q.B.; Li, G.Y. A new caffeyol phenylethanoid glycoside from the unripe fruits of Forsythia suspensa. Chin. J. Nat. Med. 2009, 7, 278-282.

4. Nishibe, S.; Tamayama, Y.; Sasahara, M.; Andary, C. A phenylethanoid glycoside from Plantago Asiatica. Phytochemistry 1995, 38, 741-743.

5. Shi, F.; Jia, X.B.; Zhao, C.L.; Chen, Y. Antioxidant activities of various extracts from Artemisisa selengensis Turcz (LuHao). Molecules 2010, 15, 4934-4946.

6. Osman, H.; Rahim, A.A.; Isa, N.M.; Bakhir, N.M. Antioxidant activity and phenolic content of Paederia foetida and Syzygium aqueum. Molecules 2009, 14, 970-978.

7. Qu, H.; Zhang, Y.; Wang, Y.; Li, B.; Sun, W. Antioxidant and antibacterial activity of two compounds (Forsythiaside and Forsythin) isolated from Forsythia suspensa. J. Pharm. Pharmacol. 2008, 60, 261-266.

8. Kuang, H.X.; Xia, Y.G.; Liang, J.; Yang, B.Y.; Wang, Q.H.; Sun, Y.P. Fast classification and compositional analysis of polysaccharides from TCMs by ultra-performance liquid chromatography coupled with multivariate analysis. Carbohydr. Polymer. 2011, 84, 1258-1266.

9. Wang, F.N.; Ma, Z.Q.; Liu, Y.; Guo, Y.Z.; Gu, Z.W. New phenylethanoid glycosides from the fruits of Forsythia Suspense (Thunb.) Vahl. Molecules 2009, 14, 1324-1331.

Sample Availability: Samples of lianqiaoxinoside B and forsythoside H are available from the authors.

(C) 2011 by the authors; licensee MDPI, Basel, Switzerland. This article is an open access article distributed under the terms and conditions of the Creative Commons Attribution license (http://creativecommons.org/licenses/by/3.0/). 